\title{
Cytosolic persistence of mouse brain CYP1A1 in chronic heme deficiency*
}

\author{
Ralf P. Meyer ${ }^{1, \star \star}$, Raija L.P. Lindberg ${ }^{2}$, Francine \\ Hoffmann ${ }^{2}$ and Urs A. Meyer ${ }^{3}$ \\ ${ }^{1}$ Department of Neuropathology, Neurozentrum, \\ University of Freiburg, Breisacherstraße 64, D-79106 \\ Freiburg, Germany \\ ${ }^{2}$ Pharmazentrum, Department of Research and \\ Neurology, Klingelbergstraße 50-70, CH-4056 Basel, \\ Switzerland \\ ${ }^{3}$ Biozentrum, Department of Pharmacology, \\ Klingelbergstraße 50-70, CH-4056 Basel, Switzerland \\ ${ }^{*}$ Corresponding author \\ e-mail: ralf.meyer@uniklinik-freiburg.de
}

\section{Introduction}

Heme is one of the body's pivotal molecules. It fulfils a vital role in cellular oxygen sensing and utilization in all living organisms from bacteria to humans (Padmanaban et al., 1989). Heme is the prosthetic group in numerous hemoproteins, including P450 cytochromes (CYPs) (Rangarajan and Padmanaban, 1989; Zhang et al., 1998; Abraham et al., 2000). CYPs play an important role in the oxidative metabolism of numerous endogenous and foreign compounds (Nelson, 2004). CYPs are active in drug metabolism and clearance, in cholesterol homeostasis, and in steroid hormone regulation, not only in the liver, but also in the brain (Thuerl et al., 1997; Meyer et al., 2001a,b; Ourlin et al., 2002; Handschin and Meyer, 2003). CYPs perform their manifold functions as functional holoenzymes saturated with heme (Correia and Meyer, 1975; Jover et al., 1996). Thus, the regulation of heme availability is of major importance for CYP function. Cellular levels of heme are regulated by its rate of synthesis and degradation by the key enzymes $\delta$-aminolevulinate synthase 1 (ALAS-1) and the heme oxygenase (HO) system (Jover et al., 1996; Maines, 2000). However, regulation of heme availability for CYPs is tissue-dependent. Previous studies in vitro and in mice, both with pharmacologically induced acute heme deficiency, have revealed differences in heme saturation of CYPs and pointed to a role of heme in the incorporation of apocytochromes into the endoplasmic reticulum (ER) membrane (Meyer et al., 2002). A regulatory heme pool tightly regulates heme synthesis in the liver, but apparently less so in extrahepatic tissue (Bissell and Hammaker, 1976b; Giger and Meyer, 1983).

Porphyrias are inherited or acquired disorders that are attributable to partial defects in the enzymes of heme synthesis (porphyrin metabolism), usually in association with endogenous or exogenous stressors (Daniell et al., 1997). In certain so-called hepatic porphyrias, patients have neuropsychiatric symptoms, including autonomic neuropathy with abdominal pain, vomiting, and hypertension, and central neuropathies, including motor weakness, paralysis and mental symptoms (Sassa, 2002). These symptoms may possibly originate from impaired heme protein function in the brain. Candidate hemoproteins in the brain are the nitric oxide synthase, guanylate cyclase system, tryptophan dioxygenase, mitochondrial cytochromes, and several isoforms of the CYP superfamily (Jover et al., 2000).

In the present study, we investigated if expression and function of CYP1A1 is affected in vivo by chronic heme deficiency in the brain. CYP1A1 is involved in the metabolic activation of polyaromatic hydrocarbons (Hankinson et al., 1991). We used a female transgenic mouse model mimicking one form of hepatic porphyria, acute intermittent porphyria (AIP). These mice carry a targeted

\footnotetext{
${ }^{*}$ Parts of this report were presented at the 15th International Symposium on Microsomes and Drug Oxidations (MDO), Mainz, Germany, July 2004. The study was awarded with the poster prize.
} 
Table 1 Heme content of mouse liver and brain after treatment with $\beta$-naphthoflavone.

\begin{tabular}{|c|c|c|c|c|c|c|}
\hline \multirow[t]{2}{*}{ Tissue } & \multirow[t]{2}{*}{ Genotype } & \multirow[t]{2}{*}{ Treatment } & \multicolumn{4}{|c|}{ Heme content } \\
\hline & & & $\begin{array}{c}\text { Specific } \\
\text { (pmol/mg protein) }\end{array}$ & $\begin{array}{c}\text { Enhancement vs. } \\
\text { controls (\%) }\end{array}$ & $\begin{array}{c}\text { Genotype influence } \\
\text { vs. } \beta-N F-W T(\%)\end{array}$ & $p$ \\
\hline \multirow{3}{*}{ Liver } & WT & None & $28.85 \pm 1.34$ & - & & \\
\hline & WT & $\beta-N F$ & $70.00 \pm 4.87$ & 242.6 & - & $\leq 0.001$ \\
\hline & $\mathrm{PBGD}^{-/-}$ & $\beta-N F$ & $59.17 \pm 2.55$ & 205.1 & -15.5 & $\leq 0.05$ \\
\hline \multirow[t]{3}{*}{ Brain } & WT & None & $13.84 \pm 0.38$ & - & & \\
\hline & WT & $\beta-N F$ & $15.96 \pm 0.52$ & 15.3 & - & $\leq 0.005$ \\
\hline & PBGD & $\beta-N F$ & $13.66 \pm 0.48$ & -1.3 & -14.4 & $\leq 0.005$ \\
\hline
\end{tabular}

WT, wild type. Specific values represent pooled organs from two mice (mean \pm SEM; $n=3$ ). Treatment with $\beta$-NF was performed as described in the materials and methods section.

disruption of porphobilinogen deaminase (PBGD), the third enzyme of the heme pathway (Lindberg et al., 1996, 1999). PBGD $^{-/-}$mice have a defined chronic disturbance of heme biosynthesis, which can be challenged by CYPinducing factors. Therefore, we treated the mice with $\beta$-naphthoflavone $(\beta-N F)$, an inducer of CYP1A1. Here we demonstrate that gene expression, heme saturation, and enzyme activity of CYP1A1 are impaired in PBGD-mice after treatment with $\beta-N F$. Our results indicate that diseases causing heme deficiency, such as AIP, could lead to impaired hemoprotein function in brain.

\section{Results}

\section{Measurement of heme content}

Initial experiments were designed to determine whether heme content in the liver and brain of mice is increased by $\beta$-NF-treatment and affected by the PBGD $^{-1-}$ genotype. In wild-type mice, $\beta-N F$ treatment increased heme content in both liver and brain, with much stronger enhancement in liver than in brain (Table 1). In PBGD ${ }^{-/}$

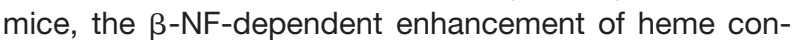
tent was lower in liver and brain compared to wild-type data (Table 1). It is noteworthy that the heme content in brains of $\beta$-NF-treated PBGD ${ }^{-/}$mice was similar to that found in untreated wild-type mice (Table 1).

\section{Regulation of cyp1a1 mRNA expression in liver}

In a subsequent experiment, we analyzed if the significant reduction in heme content of $\beta-N F$-treated $\mathrm{PBGD}^{-/}$mice compared to $\beta$-NF-treated wild-types corresponds to diminished cyp1a1 gene transcription. Therefore, the expression of mRNA in liver of untreated wild-types, $\beta$-NF-treated wild-types and $\beta$-NF-treated $\mathrm{PBGD}^{-/-}$animals was investigated by Northern blot (Figure 1). As expected, $\beta-N F$ treatment led to a significant increase in cyp1a1 mRNA transcription in both genotypes $(p \leq 0.005)$. Nevertheless, expression of cyp1a1 mRNA originating from $\beta$-NF-treated heme-deficient $\mathrm{PBGD}^{-/-}$mice was clearly lower compared to $\beta$-NF-treated wild-type mice (Figure 1, lanes 1 and 2), indicating a negative effect of PBGD deletion and reduced heme availability for cyp1a1 gene transcription $(p \leq 0.05)$. No mRNA was detectable in untreated liver (Figure 1, lane 3). This finding is due to the fact that gene transcription of cyp1a1 is usually very low in untreated animals (Gon- zalez, 1990). GAPDH control data showed no difference (Figure 1).

\section{Expression of CYP1A1 protein in cellular subfractions of liver and brain}

We next investigated by immunoblot how $\beta-N F$ treatment and heme deficiency affect expression and subcellular localization of CYP1A1 protein in liver and brain (Figure 2). In the liver, the genotype-dependent inducibility of CYP1A1 protein was in accordance with our findings investigating mRNA expression (see Figure 1). $\beta-N F$ treatment led to the expected induction of CYP1A1 in both wild-types and PBGD ${ }^{-/}$mice $(p \leq 0.001)$, but with less potency in subfractions of $\mathrm{PBGD}^{-/-}$mice, for which a lower CYP1A1 protein signal was observed compared to wild-type mice (Figure 2A) $(p \leq 0.05)$. CYP1A1 was located almost exclusively in microsomes, independent of treatment and genotype.

In brain, we observed a striking difference in CYP1A1 expression between $\beta$-NF-treated wild-types and $\mathrm{PBGD}^{-/-}$mice (Figure 2B). $\beta-\mathrm{NF}$ treatment led to a 1.4fold increase in CYP1A1 in microsomes of wild-types compared to $\mathrm{PBGD}^{--}$mice $(p \leq 0.001)$. In addition, cytosolic CYP1A1 was detected, which was two-fold higher in the $\mathrm{PBDG}^{-/}$mice compared to the wild-type animals $(p \leq 0.05)$. In untreated mice, CYP1A1 was not detectable in the brain (Figure 2B).

\section{Ethoxyresorufin-O-deethylase (EROD) activity of CYP1A1 in mouse brain is dependent on genotype and $\beta-N F$ induction}

The investigation of CYP1A-specific EROD activity in brain subfractions matched our findings from immunoblotting experiments. In untreated mice, no or only negligible EROD activity could be found in any subfraction, whereas treatment of the mice with $\beta-N F$ led to remarkable increase in EROD activity in all subfractions tested (Figure 3). EROD activity was found predominantly in the microsomes, with no significant differences between wild-types and $\mathrm{PBGD}^{-/-}$mice (Figure $3 \mathrm{~A}$ ). The EROD activity detectable in the cytosol revealed clear dependence on genotype after treatment of mice with $\beta-N F$. Cytosolic EROD activity of $\mathrm{PBGD}^{-/-}$mice appeared to be two-fold higher than in wild-types, which reflects a remarkable fraction of non-membrane bound CYP1A1 in the brain (Figure $3 A)(p \leq 0.005)$. This genotype-dependent difference in cytosolic EROD activity remained, 
cyp1a1

GAPDH

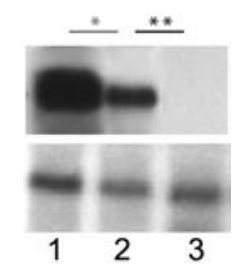

Figure 1 Expression of cyp1a1 mRNA in liver from wild type and $\mathrm{PBGD}^{-/-}$mice (Northern blot analysis).

(1) $\beta$-NF-induced wild types; (2) $\beta-N F$-induced $\mathrm{PBGD}^{-/-}$mice; and (3) untreated wild types, with $5 \mu \mathrm{g}$ of total RNA loaded on each lane. In the case of cyp1a1 mRNA, a 294-bp probe located on exon 7 was used for hybridization (see materials and methods). GAPDH was used as a reference. Statistical significance is demonstrated by asterisks $\left({ }^{* *} p \leq 0.005 ;{ }^{*} p \leq 0.05\right)$.

although less striking, after the addition of $8 \mu \mathrm{M}$ hematin (Figure 3B). Addition of hematin is reported to saturate and reconstitute the CYP apoprotein fraction (Omiecinski et al., 1980). We observed a three-fold enhancement of EROD activity in cytosol in $\mathrm{PBGD}^{-/-}$mice, and five-fold enhancement in wild-types, after the addition of hematin (Figure 3B). In microsomes, however, hematin caused a reduction in EROD activity $(p \leq 0.05)$.

\section{Gene products of cyp1a1}

To examine if cytosolic CYP1A1 originates from an allelic or splice variant of cyp1a1 leading to either cytosolic or microsomal protein, we generated a gene-specific probe designed to recognize sequences of exon 7 . This probe should allow the detection of CYP1A1 gene products with differences in the membrane-anchoring sequence (Gonzalez et al., 1984) (Figure 4A).

However, hybridization of mouse genomic DNA obtained from wild-type and PBGD ${ }^{-1-}$ mice with the 294bp probe revealed that, most likely, only one cyp $1 a 1$ gene product exists in the mouse, independent of the genotype (Figure 4B). Therefore, the solubility of CYP1A1 in brain may not originate from an allelic or splice variant of the cyp1a1 gene.

\section{Discussion}

CYP1A1 is expressed predominantly in extrahepatic tissue and abundantly in brain (McFayden et al., 1998; Iba et al., 2003). Our previous in vitro studies have suggested that heme deficiency leads to increased accumulation of CYP1A1 in the cytosol of COS-1 cells and untreated male mice (Meyer et al., 2002). This is supported by the present in vivo data in female $\mathrm{PBGD}^{-/-}$mice. The $\mathrm{PBGD}^{-/-}$mouse provides a unique model of chronic impairment of heme synthesis (Lindberg et al., 1996, 1999). After $\beta$-NF-treatment, the chronic partial heme deficiency in these mice led to impaired CYP1A1 expression and enzyme activity in mouse liver and brain. More surprisingly, CYP1A1 protein and activity were detected in increased amounts in the cytosol of mouse brain after $\beta-\mathrm{NF}$ treatment of $\mathrm{PBGD}^{-/-}$mice compared to wild-type mice. The use of female mice in the present in vivo study has the advantage that, in contrast to males (Meyer et al., 2002), in untreated mice, CYP1A1 mRNA, protein and EROD activity were not detectable in both liver and brain. CYP1A1 protein is known to be highly inducible in several brain regions, corresponding to elevated levels of microsomal EROD activity (Morse et al., 1998). Therefore, the genotype-dependent effects of the CYP1A1 inducer $\beta-N F$ on heme content, CYP1A1 expression and enzyme activity under conditions of chronic heme deficiency, as investigated in the present study, substantially extend data from our previous in vitro study mimicking the untreated situation (Meyer et al., 2002).

We have speculated that the availability of heme efficiently regulates the incorporation of apocytochrome CYP1A1 into the ER membrane, at least in extrahepatic tissue. Interestingly, this effect of heme deficiency, leading to cytosolic accumulation of CYP1A1, is not observed in the liver (Omiecinski and Juchau, 1980; Meyer et al., 2002). This can be explained by the efficient adaptation of ALAS-1 to increased heme demands, such as drug treatment, in liver and intestine, which is mediated by nuclear receptor signaling by CAR and PXR (Fraser et al., 2003). In extrahepatic tissue, ALAS-1 obviously adapts differently to heme demands or drug treatment, as stimulation of ALAS-1 by drugs is less marked than in the liver (Reed et al., 1989). Although the brain produces heme required for synthesis and turnover of its own hemoproteins (De Matteis et al., 1981), most of the constitutively synthesized heme is used for cell homeostasis and the generation of carbon monoxide and nitric oxide, and is not drug inducible (Ingi et al., 1996; Jover et al., 2000; da Silva et al., 2001). Heme oxidation in brain is effectively controlled and balanced by the activity of the heme oxygenase isoforms $\mathrm{HO}-1$ and $\mathrm{HO}-2$ (Maines, 2000).

Moreover, administration of exogenous heme to porphyria patients and to healthy volunteers increased P450-mediated drug metabolism (Bonkovsky et al., 1991). Our present study suggests that this increase is due to heme effects in extrahepatic tissues, reconstituting undersaturated apocytochromes and/or leading to greater incorporation of cytoplasmic apocytochromes into the ER membrane, elevating their enzyme activity. This concept is corroborated by significantly enhanced levels of cytosolic EROD activity in $\beta$-NF-treated mice after the exogenous addition of hematin. Extrahepatic CYP apoproteins are reported to have low affinity for their heme prosthetic group, but a comparatively high turnover number when in the holoenzyme state (Omiecinski et al., 1980). The effect of hematin in lowering microsomal EROD activity may be explained by the fact that, after induction, the membrane-bound fraction of CYP1A1 is in the holoenzyme state and excessive heme may be inhibitory (Namkung et al., 1983). Conversely, this concept of high turnover numbers of extrahepatic CYPs in the holoenzyme state can most likely explain our finding that, if no exogenous heme is added, there is largely no difference in microsomal EROD activity after $\beta$-NF induction between wild-type and $\mathrm{PBGD}^{-/-}$mice, whereas CYP1A1 protein is clearly reduced in PBGD ${ }^{-/-}$mice.

The mechanistic aspects of heme incorporation into CYP apoproteins and the role of this process in membrane incorporation is still poorly understood. Our observation that heme deficiency leads to cytosolic 


\section{A Liver}

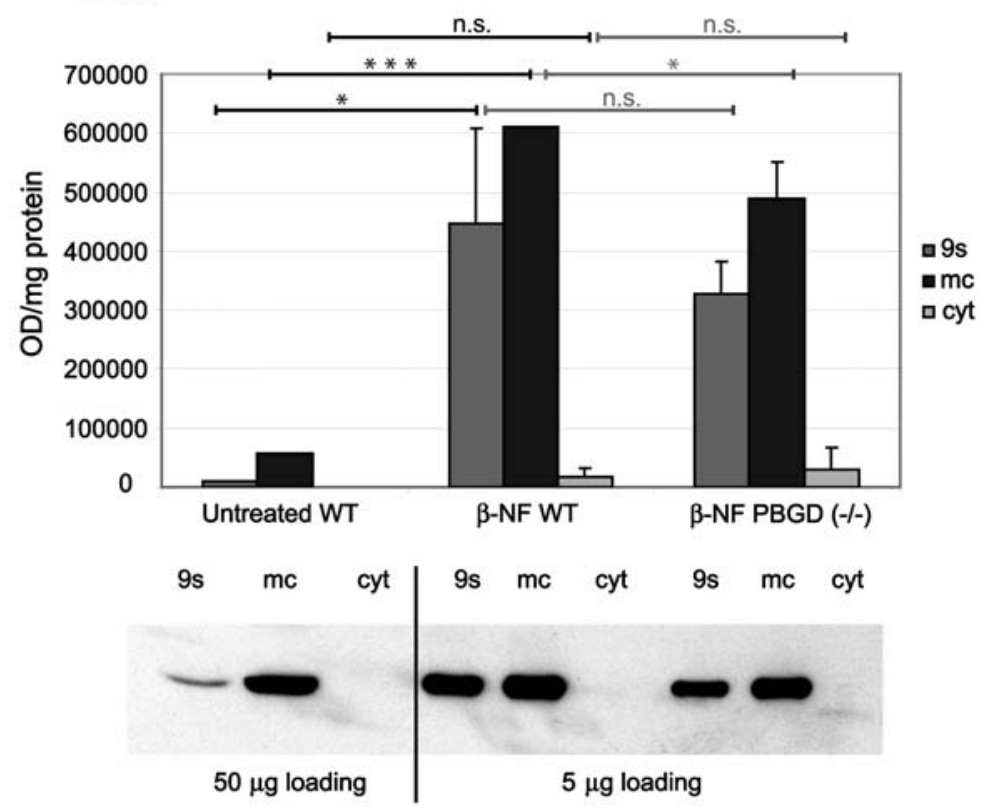

\section{B Brain}

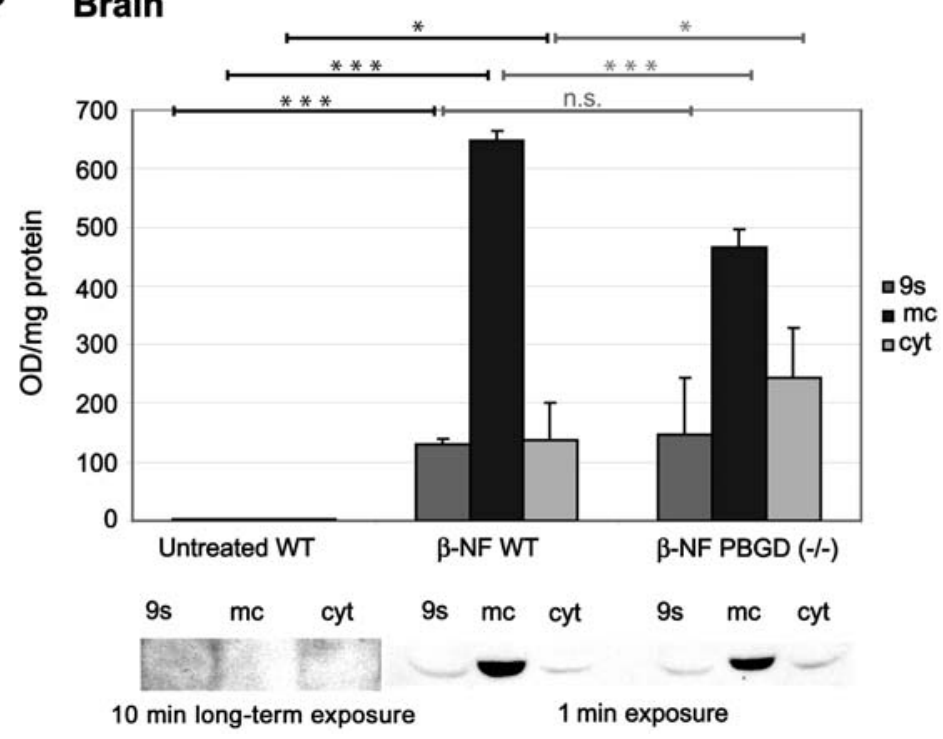

Figure 2 Expression of CYP1A1 protein in subfractions of liver and brain of wild-type and PBGD $/-$ mice. Scanning densitometry evaluation of immunoblots with monoclonal antibodies mab 1-7-1 raised against CYP1A1 (Park et al., 1982). (A) CYP1A1 immunoblot of liver subfractions from female mice. Values represent a pool of two untreated animals and a pool of two $\beta$-NF-treated animals of each genotype (mean $\pm S E M ; n=3$ ) The mapped blot is a representative of these experiments. (B) CYP1A1 immunoblot of brain subfractions from female mice. Values represent a pool of four untreated animals and a pool of two $\beta$-NF-treated animals of each genotype (mean \pm SEM; untreated, $n=3 ; \beta-N F$-treated, $n=4$ ). The mapped blot is a representative of these experiments. Protein from $9000 \mathrm{~g}$ supernatant $(9 \mathrm{~s})$, microsomes $(\mathrm{mc}$ ) and cytosol (cyt) were separated by SDS-PAGE. Immunosignals were visualized using enhanced chemiluminescence (ECL). Statistical significance is demonstrated by asterisks $\left({ }^{* * *} p \leq 0.001 ;{ }^{*} p \leq 0.05 ; n . s\right.$., not significant).

accumulation of CYP1A1 may be important for further clarification of this process. Several previous studies provided evidence for the concept that heme incorporation and exchange as well as membrane insertion of CYP isoforms is a dynamic process between the cytoplasm and ER membranes. The biosynthesis of apocytochrome was shown to precede that of heme, so that incorporation of heme into the nascent apoprotein must take place prior to or in close relation to membrane insertion (Meier et al., 1984; De Matteis and Marks, 1996). Furthermore, CYP heme can dissociate reversibly from its apoprotein to allow heme exchange (Bissell and Hammaker, 1976a). It was suggested from studies in testis that a less stable form of CYP may be present in extrahepatic tissues that shows impaired association with heme (Maines and Jollie, 1984). These data corroborate our findings that a small but significantly regulated fraction of enzymatically active CYP1A1 holoenzyme is present in the cytosol of wild-type and $\mathrm{PBGD}^{-/-}$mice (Figure $3 \mathrm{~A}$ ).

We presume that the availability of heme differentially regulates the amount of specific CYP isoforms. We have demonstrated that partial chronic heme deficiency led to 
A

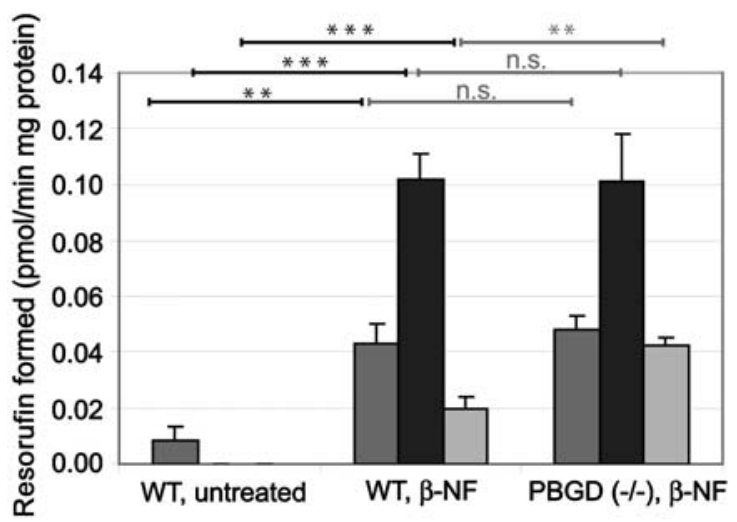

B

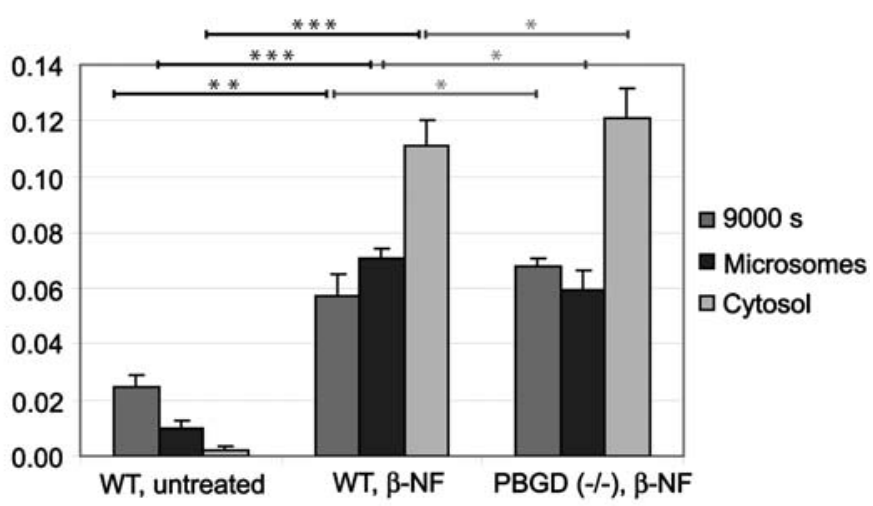

Figure 3 Formation of resorufin by 7-deethylation of 7-ethoxyresorufin in subfractions of mouse total brain from untreated and $\beta$-NF-treated wild-type and PBGD ${ }^{-1-}$ mice.

Incubations were performed with $6 \mu \mathrm{M}$ 7-ethoxyresorufin $(A)$ and in the presence of $8 \mu \mathrm{M}$ hematin (B). Values represent a pool of four untreated animals, and a pool of two $\beta$-NF-treated animals of each genotype (mean $\pm S E M ; n=3$ ). Statistical significance is demonstrated by asterisks $\left({ }^{* \star *} p \leq 0.001 ;{ }^{\star \star} p \leq 0.005 ;{ }^{*} p \leq 0.05\right.$; n.s., not significant).

less potent induction of cyp1a1 mRNA in liver after treatment of $\mathrm{PBGD}^{-1-}$ mice with $\beta-\mathrm{NF}$. This is consistent with significant inhibition of CYP2A5 in liver of these $\mathrm{PBGD}^{-1-}$ mice after phenobarbital treatment (Jover et al., 2000). The mechanism by which impaired heme synthesis decreases CYP expression is not completely understood and is still the subject of some controversy. Several

A

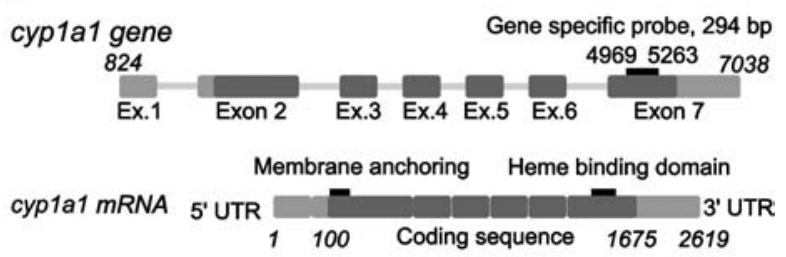

B

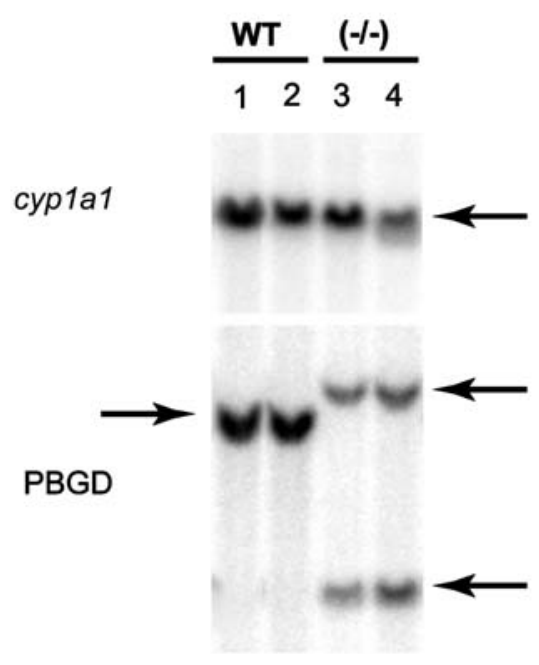

Figure 4 Detection of gene products of CYP1A1 and PBGD with gene-specific probes by Southern blot analysis.

(A) Schematic representation of cyp1a1 gene and mRNA structure. Localization of the cyp1a1 gene-specific probe, the hemebinding domain and the membrane-anchoring domain are indicated. (B) Phosphoimage of the hybridization of genomic DNA from wild-type and PBGD $/-$ mice with $\left[\alpha{ }^{-32} \mathrm{P}\right]-A T P-l a b e l e d$ CYP1a1 and PBGD gene-specific probes. The DNA was digested with EcoRI. reports demonstrate that heme stabilizes the mRNA of target genes and is therefore required for effective gene transcription, e.g., for CYP1A1, CYP2B1/2 and HO-1 (Kloepper-Sams and Stegeman, 1994; Sultana et al., 1997; Alam et al., 2003). Consistent with these studies, we speculate that heme deficiency may lead to impaired CYP1A1 mRNA stability, which results in reduced gene transcription. However, other studies showed that some CYP isoforms, including cyp2b10 and CYP2B1/2, revealed less or no modulation of CYP MRNA in liver by partial heme deficiency (Hamilton et al., 1988; Jover et al., 2000). Furthermore, other hemoproteins, namely neuronal nitric oxide synthase and soluble guanylate cyclase, are reported to function normally in mice with limited heme (Jover et al., 2000). Our findings are in agreement with previous clinical studies in porphyria patients and healthy volunteers showing that the effect of heme in increasing drug metabolism is related to specific CYP isoforms (Mustajoki et al., 1994). Currently, we are investigating the isoform specificity of this effect using GFPfused CYP1A, CYP2C, and CYP3A isoforms. This may provide information about subcellular localization and the regulation of these CYPs after drug treatment or pharmacologically induced heme deficiency.

In conclusion, the results of the present study suggest that partial chronic heme deficiency affects cyp1a1 expression, as well as CYP1A1 holoenzyme function. In partial heme deficiency, CYP1A1 in brain is incompletely saturated with heme. Incorporation of the isoform into ER membranes is impaired and it remains in the cytosol. Consequently, the enzyme activity of CYP1A1 is altered. This concept may apply to other extrahepatic P450 cytochromes and other hemoproteins. Diseases causing heme deficiency, such as AIP, could apparently lead to impaired hemoprotein function in brain. It has been strongly suggested that symptoms such as autonomic or peripheral neuropathies originate from such impaired brain hemoprotein function rather than from the putative neurotoxic heme precursor $\delta$-aminolevulinic acid (ALA), as the neuropathy in $\mathrm{PBGD}^{-/-}$mice developed in the presence of almost normal ALA levels (Lindberg et al., 1999; Schuurmans et al., 2001; Sassa, 2002). Therefore, the 
present study on CYP1A1 regulation in heme-deficient mice may contribute to the understanding of CYP function and regulation in brain and the proceeding mechanisms in chronic heme deficiency.

\section{Materials and methods}

\section{Animals}

Three female C57BI/6J mice (age 1 year) of each genotype (wild type or $\mathrm{PBGD}^{-/}$) were injected twice intraperitoneally with $80 \mathrm{mg}$ $\beta-N F / k g$ in corn oil. Four female wild-type mice were used as controls. The animals were maintained in a 12-h light/dark cycle in a controlled-environment animal facility and had free access to standard rodent chow and tap water. Mice were anesthetized with sodium pentobarbital, the left ventricle of the heart was punctured and the animal was perfused with cold isotonic saline to remove blood from the organs. Livers and brains were excised, frozen in liquid nitrogen and stored at $-80^{\circ} \mathrm{C}$ until use.

\section{Chemicals}

7-Ethoxyresorufin, resorufin, and $\beta$-NF were purchased from Aldrich (Buchs, Switzerland). Bovine serum albumin and NADPH were obtained from Sigma (Buchs, Switzerland). Glucose-6phosphate, glucose-6-phosphate dehydrogenase, PCR free nucleotide premix and the DNA ladder were purchased from Roche Diagnostics (Mannheim, Germany). Protoporphyrin IX fluorescence standard and hemin were purchased from Porphyrin Products (Logan, UT, USA). Trizol-RNA preparation kit and M-MLV reverse transcriptase were obtained from Life Technologies (Basel, Switzerland). Gel purification and DNA preparation kits were purchased from Qiagen (Basel, Switzerland). For cloning, the pGEM-T easy vector (Promega-Catalys AG, Wallisellen, Switzerland) was used. Taq-DNA polymerase was obtained from Perkin-Elmer (Rotkreuz, Switzerland). PCR primers were synthesized by Intron (Kaltbrunn, Switzerland). All other reagents were from commercial sources at the highest purity available.

\section{RNA purification, cDNA synthesis and probe generation}

Total RNA of frozen tissue was isolated using the Trizol-RNA purification protocol (Life Technologies). RNA was reverse-transcribed in $50 \mathrm{~mm}$ Tris- $\mathrm{HCl}, \mathrm{pH} 8.3,75 \mathrm{~mm} \mathrm{KCl}, 10 \mathrm{~mm}$ dithiothreitol (DTT), $3 \mathrm{mM} \mathrm{MgCl}, 200 \mu \mathrm{M}$ of each deoxynucleotide triphosphate, $200 \mathrm{U} / \mu \mathrm{g}$ RNA M-MLV reverse transcriptase, $28 \mathrm{U}$ of ribonuclease inhibitor (RNAsin, Promega, Madison, WI, USA) and $2 \mu \mathrm{M}$ oligo $\left[\mathrm{dT}_{14}(\mathrm{~A} / \mathrm{C} / \mathrm{G})\right]$ primer. The mixture was incubated at $40^{\circ} \mathrm{C}$ for $1 \mathrm{~h}$.

Specific primers for the gene-specific cyp1a1 probe were designed as follows: the cyp1a1 forward primer (sense strand) corresponded to nucleotides 1375-1393 (5'-GGG TGA CCC AAA CGA GTT-3'), and the cyp1a1 reverse primer to nucleotides 1669-1687 (5'-TGA AGA TGC TGA GGA CCA-3') (GenBank accession number K02588). As a loading control, a gene-specific probe for detection of the standard sn-glyceraldehydephosphate dehydrogenase (GAPDH) was used (Lindberg et al., 1996).

\section{Analysis of mRNA using Northern blotting}

For analysis of mRNA by the Northern blot technique we generally followed the protocol described by Sambrook et al. (1989). A 5- $\mu \mathrm{g}$ sample of liver total RNA was subjected to denaturing electrophoresis on $1 \%$ agarose formaldehyde gels using 3-(Nmorpholino)propanesulfonic acid (MOPS) as buffering substance as described by Sambrook et al. (1989). The gel was run for $4 \mathrm{~h}$ at $80 \mathrm{~V}$ (constant voltage). RNA was then transferred to a nylon membrane (GeneScreen, NEN Research Products, Boston, MA, USA) by blotting overnight in $10 \times$ SSC buffer (150 mM NaCl, $15 \mathrm{~mm}$ sodium citrate). The RNA was attached to the membrane by UV cross-linking (Stratagene, Basel, Switzerland). Hybridization was carried out in buffer containing $50 \%$ deionised formamide, $5 \times$ SSC, $5 \times$ Denhardt's solution, $1 \%$ SDS and $10 \%$ $(\mathrm{w} / \mathrm{v})$ dextran sulfate. Before being added to the hybridization solution, the PCR-labeled probe was boiled for $5 \mathrm{~min}$ in $300 \mu \mathrm{l}$ of $10 \mathrm{mg} / \mathrm{ml}$ salmon sperm DNA and quickly chilled on ice. Hybridization was carried out for $20 \mathrm{~h}$ at $42^{\circ} \mathrm{C}$. Washes were performed in $2 \times \mathrm{SSC} / 0.1 \%$ SDS at RT for $30 \mathrm{~min}$ and in $2 \times$ $\mathrm{SSC} / 1 \% \mathrm{SDS}$ at $65^{\circ} \mathrm{C}$ for $10-20 \mathrm{~min}$. Membranes were exposed to $X$-ray film using intensifying screens.

\section{Analysis of genomic DNA using Southern blotting}

Genomic DNA from wild-type and PBGD $/-$ mice was used for Southern blotting. The DNA was digested with EcoRI and transferred to a GeneScreen nylon membrane as described by Lindberg et al. (1996). Hybridization was carried out in buffer containing $1 \mathrm{M} \mathrm{NaCl}, 1 \%$ SDS and $10 \%(\mathrm{w} / \mathrm{v})$ dextran sulfate. Before being added to the hybridization solution, the [ $\left.{ }^{32} \mathrm{P}\right]-\mathrm{PCR}-$ labeled probe was boiled for $5 \mathrm{~min}$ in $400 \mu \mathrm{l}$ of $10 \mathrm{mg} / \mathrm{ml}$ salmon sperm DNA and quickly chilled on ice. Hybridization was carried out for $15 \mathrm{~h}$ at $65^{\circ} \mathrm{C}$. Washes were performed twice in $2 \times$ $\mathrm{SSC} / 0.1 \%$ SDS at RT for $5 \mathrm{~min}$ and in $2 \times \mathrm{SSC} / 1 \%$ SDS at $65^{\circ} \mathrm{C}$ for 10-20 min. Membranes were exposed to X-ray film using intensifying screens.

\section{Homogenization and subfractionation of mouse tissue}

Homogenization and subfractionation of mouse tissue was performed as described previously (Meyer et al., 2002). Homogenate was centrifuged at $9000 \mathrm{~g}$ (Omiecinski et al., 1980). The $9000 \mathrm{~g}$ supernatant was then ultracentrifuged at $170000 \mathrm{~g}\left(r_{\max }\right)$ for 30 min at $4^{\circ} \mathrm{C}$ using a Beckman TLA120.2 rotor in a Beckman bench-top ultracentrifuge. The $170000 \mathrm{~g}$ pellet was designated as 'microsomes', and the $170000 \mathrm{~g}$ supernatant as 'cytosol'. The protein content of the subfractions was measured according to Lowry et al. (1951). NADPH-cytochrome P450 oxidoreductase was used as a marker to check membranous contamination of the cytosol (Näslund et al., 1988). All methods used were proved to generate high-integrity subcellular organelles and cytosol with negligible membranous contamination (Meyer et al., 2002).

\section{Ethoxyresorufin-O-deethylase (EROD) assay}

EROD was measured according to the method of Burke et al. (1985), using an end-point fluorimetric determination. Samples equivalent to a protein amount of $40 \mu \mathrm{g}$ for liver or $200 \mu \mathrm{g}$ for brain were preincubated in $100 \mathrm{~mm}$ sodium phosphate buffer, $\mathrm{pH} 7.4$, containing $20 \%$ glycerol, $0.2 \mathrm{~mm}$ EDTA, $0.5 \mathrm{~mm}$ DTT, $5 \mathrm{~mm} \mathrm{MgC1} 1_{2}, 1 \mathrm{mg} / \mathrm{ml}$ bovine serum albumin, $6 \mu \mathrm{M}$ substrate, and $3.4 \mu \mathrm{g}$ of purified rat cytochrome $c$ reductase for $2 \mathrm{~min}$ at $37^{\circ} \mathrm{C}$. NADPH $(0.5 \mathrm{~mm})$ was added and the reaction was allowed to proceed for $15 \mathrm{~min}$ or $2 \mathrm{~h}$ at $37^{\circ} \mathrm{C}$ in darkness and under $100 \%$ oxygen (Omiecinski et al., 1980). Freshly prepared hematin (Correia and Meyer, 1975) at a concentration of $8 \mu \mathrm{M}$ was added to the reaction mixture $5 \mathrm{~min}$ after the start. Incubation was stopped by the addition of methanol and the mixture was centrifuged at $14000 \mathrm{~g}$ for $10 \mathrm{~min}$. Fluorescence of the product and identically handled resorufin standards were measured using a Perkin-Elmer LS50B luminescence photometer (Perkin Elmer). An identical set of samples boiled for $15 \mathrm{~min}$ at $95^{\circ} \mathrm{C}$ was used as blanks. 


\section{Immunoblot using monoclonal antibody mab-1-7-1 against CYP1A1}

Protein from subfractions of liver ( 50 and $5 \mu \mathrm{g} /$ lane for untreated and $\beta$-NF-treated mice, respectively) and brain (500 $\mu \mathrm{g} / \mathrm{lane})$ was precipitated with methanol and resolved on $9 \%$ SDS polyacrylamide gels. Proteins were transferred to polyvinylidene difluoride (PVDF) membranes (Immobilon P, Millipore AG, Volketswil, Switzerland) in buffer (125 mM Tris, $960 \mathrm{~mm}$ glycine). Incubations were performed with anti-CYP1A1 monoclonal antibody mab-1-7-1 (diluted 1:500) (Park et al., 1982), followed by exposure to horseradish peroxidase-conjugated IgG (goat antimouse) at a dilution of 1:3000. The immunopositive bands were visualized with enhanced chemiluminescence (ECL; AmershamPharmacia GmbH, Dübendorf, Switzerland). The intensity of the immunostained bands was evaluated by scanning densitometry using Tina 2.10 software (Raytest $\mathrm{GmbH}$, Straubenhardt, Germany), and the results were analyzed statistically.

\section{Heme determination}

Heme content was determined by measurement of protoporphyrin IX fluorescence as previously described (Carvalho et al., 1997; Meyer et al., 2002). Brain or liver tissue was treated with $2 \mathrm{M}$ oxalic acid $(100 \mu \mathrm{l})$ at $95^{\circ} \mathrm{C}$ for $30 \mathrm{~min}$. Samples were subsequently resuspended in $900 \mu \mathrm{l}$ of PBS and centrifuged at $15000 \mathrm{~g}$ for $15 \mathrm{~min}$. Fluorescence emission in the supernatant was determined spectrofluorimetrically (Perkin Elmer LS50B). Excitation and emission wavelengths were set to 405 and $600 \mathrm{~nm}$, respectively. The background was evaluated by measuring fluorescence in non-boiled samples. A standard curve of protoporphyrin IX was run in parallel.

\section{Statistical analysis}

Data were analyzed statistically using an unpaired two-group t-test (two-tailed t-test) to demonstrate the influence of both $\beta-N F$ treatment and genotype. Data processing was performed using Microsoft Excel 2003 and SPSS 11.0.1 software. Results were considered significant with $p \leq 0.05$ for alterations due to $\beta$-NF treatment or genotype. In cases where $\beta$-NF or different genotype did not cause an effect $(p>0.05)$ the results were considered not significant (n.s.).

\section{Acknowledgments}

This study was supported by grants from the Deutsche Forschungsgemeinschaft (DFG Me 1544/1-1 and Me 1544/4-1) (to R.P.M.) and the Swiss National Science Foundation (to U.A.M.).

\section{References}

Abraham, N.G., Jiang, S., Yang, L., Zand, B.A., LaniadoSchwartzman, M., Marji, J., Drummond, G.S., and Kappas, A. (2000). Adenoviral vector-mediated transfer of human heme oxygenase in rats decreases renal heme-dependent arachidonic acid epoxygenase activity. J. Pharmacol. Exp. Ther. 293, 494-500.

Alam, J., Killeen, E., Gong, P., Naquin, R., Hu, B., Stewart, D., Ingelfinger, J.R., and Nath, K.A. (2003). Heme activates the heme oxygenase-1 gene in renal epithelial cells by stabilizing Nrf2. Am. J. Physiol. Renal Physiol. 284, F743-F752.

Bissell, D.M. and Hammaker, L.E. (1976a). Cytochrome P-450 heme and the regulation of delta-aminolevulinic acid synthetase in the liver. Arch. Biochem. Biophys. 176, 103-112.
Bissell, D.M. and Hammaker, L.E. (1976b). Cytochrome P-450 heme and the regulation of hepatic heme oxygenase activity. Arch. Biochem. Biophys. 176, 91-102.

Bonkovsky, H.L., Healey, J.F., Lourie, A.N., and Gerron, G.G. (1991). Intravenous heme-albumin in acute intermittent porphyria: evidence for repletion of hepatic hemoproteins and regulatory heme pools. Am. J. Gastroenterol. 86, 1050-1056.

Burke, M.D., Thompson, S., Elcombe, C.R., Halpert, J., Haaparanta, T., and Mayer, R.T. (1985). Ethoxy-, pentoxy- and benzyloxyphenoxazones and homologues: a series of substrates to distinguish between different induced cytochromes P-450. Biochem. Pharmacol. 34, 3337-3345.

Carvalho, H., Bechara, E.J., Meneghini, R., and Demasi, M. (1997). Haem precursor $\delta$-aminolaevulinic acid induces activation of the cytosolic iron regulatory protein 1 . Biochem. J. 328, 827-832.

Correia, M.A. and Meyer, U.A. (1975). Apocytochrome P-450: reconstitution of functional cytochrome with hemin in vitro. Proc. Natl. Acad. Sci. USA 72, 400-404.

da Silva, J.L., Zand, B.A., Yang, L.M., Sabaawy, H.E., Lianos, E., and Abraham, N.G. (2001). Heme oxygenase isoform-specific expression and distribution in the rat kidney. Kidney Int. $59,1448-1457$.

Daniell, W.E., Stockbridge, H.L., Labbe, R.F., Woods, J.S., Anderson, K.E., Bissell, D.M., Bloomer, J.R., Ellefson, R.D., Moore, M.R., Pierach, C.A., et al. (1997). Environmental chemical exposures and disturbances of heme synthesis. Environ. Health Perspect. 105 (Suppl. 1), 37-53.

De Matteis, F. and Marks, G.S. (1996). Cytochrome P450 and its interactions with the heme biosynthetic pathway. Can. J. Physiol. Pharmacol. 74, 1-8.

De Matteis, F., Zetterlund, P., and Wetterberg, L. (1981). Brain 5aminolaevulinate synthase. Developmental aspects and evidence for regulatory role. Biochem. J. 196, 811-817.

Fraser, D.J., Zumsteg, A., and Meyer, U.A. (2003). Nuclear receptors constitutive androstane receptor and pregnane $\mathrm{X}$ receptor activate a drug-responsive enhancer of the murine 5-aminolevulinic acid synthase gene. J. Biol. Chem. 278, 39392-39401.

Giger, U. and Meyer, U.A. (1983). Effect of succinylacetone on heme and cytochrome P450 synthesis in hepatocyte culture. FEBS Lett. 153, 335-338.

Gonzalez, F.J. (1990). Molecular genetics of the P-450 superfamily. Pharmacol. Ther. 45, 1-38.

Gonzalez, F.J., Mackenzie, P.I., Kimura, S., and Nebert, D.W. (1984). Isolation and characterization of full-length mouse cDNA and genomic clones of 3-methylcholanthrene-inducible cytochrome P1-450 and P3-450. Gene 29, 281-292.

Hamilton, J.W., Bement, W.J., Sinclair, P.R., Sinclair, J.F., and Wetterhahn, K.E. (1988). Expression of 5-aminolaevulinate synthase and cytochrome P-450 mRNAs in chicken embryo hepatocytes in vivo and in culture. Effect of porphyrinogenic drugs and haem. Biochem. J. 255, 267-275.

Handschin, C. and Meyer, U.A. (2003). Induction of drug metabolism: the role of nuclear receptors. Pharmacol. Rev. 55, 649-673.

Hankinson, O., Brooks, B.A., Weir-Brown, K.I., Hoffman, E.C., Johnson, B.S., Nanthur, J., Reyes, H., and Watson, A.J. (1991). Genetic and molecular analysis of the Ah receptor and of Cyp1a1 gene expression. Biochimie 73, 61-66.

Iba, M.M., Storch, A., Ghosal, A., Bennett, S., Reuhl, K.R., and Lowndes, H.E. (2003). Constitutive and inducible levels of CYP1A1 and CYP1A2 in rat cerebral cortex and cerebellum. Arch. Toxicol. 77, 547-554.

Ingi, T., Chiang, G., and Ronnett, G.V. (1996). The regulation of heme turnover and carbon monoxide biosynthesis in cultured primary rat olfactory receptor neurons. J. Neurosci. 16, 5621-5628.

Jover, R., Hoffmann, K., and Meyer, U.A. (1996). Induction of 5 -aminolevulinate synthase by drugs is independent of increased apocytochrome P450 synthesis. Biochem. Biophys. Res. Commun. 226, 152-157. 
Jover, R., Hoffmann, F., Scheffler-Koch, V., and Lindberg, R.L. (2000). Limited heme synthesis in porphobilinogen deaminase-deficient mice impairs transcriptional activation of specific cytochrome P450 genes by phenobarbital. Eur. J. Biochem. 267, 7128-7137.

Kloepper-Sams, P.J. and Stegeman, J.J. (1994). Turnover of hepatic microsomal cytochrome P4501A protein and heme in beta-naphthoflavone-induced Fundulus heteroclitus. Mol. Mar. Biol. Biotechnol. 3, 171-183.

Lindberg, R.L.P., Porcher, C., Grandchamp, B., Ledermann, B., Bürki, K., Brandner, S., Aguzzi, A., and Meyer, U.A. (1996). Porphobilinogen deaminase deficiency in mice causes a neuropathy resembling that of human hepatic porphyria. Nat. Genet. 12, 195-199.

Lindberg, R.L., Martini, R., Baumgartner, M., Erne, B., Borg, J., Zielasek, J., Ricker, K., Steck, A., Toyka, K.V., and Meyer, U.A. (1999). Motor neuropathy in porphobilinogen deaminase-deficient mice imitates the peripheral neuropathy of human acute porphyria. J. Clin. Invest. 103, 1127-1134.

Lowry, O.H., Rosebrough, N.J., Farr, A.L., and Randall, R.J. (1951). Protein measurement with the Folin phenol reagent. J. Biol. Chem. 193, 265-275.

Maines, M.D. (2000). The heme oxygenase system and its functions in the brain. Cell Mol. Biol. 46, 573-585.

Maines, M.D. and Jollie, D.R. (1984). Dissociation of heme metabolic activities from the microsomal cytochrome P-450 turnover in testis of hypophysectomized rats. J. Biol. Chem. 259, 9557-9562.

McFayden, M.C., Melvin, W.T., and Murray, G.I. (1998). Regional distribution of individual forms of cytochrome P450 mRNA in normal adult human brain. Biochem. Pharmacol. 55, 825-830.

Meier, P.J., Gasser, R., Hauri, H.P., Stieger, B., and Meyer, U.A. (1984). Biosynthesis of rat liver cytochrome P-450 in mitochondria-associated rough endoplasmic reticulum and in rough microsomes in vivo. J. Biol. Chem. 259, 10194-10200.

Meyer, R.P., Hagemeyer, C.E., Knoth, R., Kurz, G., and Volk, B. (2001a). Oxidative hydrolysis of scoparone by cytochrome P450 Cyp2c29 reveals a novel metabolite. Biochem. Biophys. Res. Commun. 285, 32-39.

Meyer, R.P., Knoth, R., Schiltz, E., and Volk, B. (2001b). Possible Function of astrocyte cytochrome P450 in control of xenobiotic phenytoin in the brain: in vitro studies on murine astrocyte primary cultures. Exp. Neurol. 167, 376-384.

Meyer, R.P., Podvinec, M., and Meyer, U.A. (2002). Cytochrome P450 CYP1A1 accumulates in the cytosol of kidney and brain and is activated by heme. Mol. Pharmacol. 62, 1061-1067.

Morse, D.C., Stein, A.P., Thomas, P.E., and Lowndes, H.E. (1998). Distribution and induction of cytochrome P450 1A1 and 1A2 in rat brain. Toxicol. Appl. Pharmacol. 152, 232-239.

Mustajoki, P., Mustajoki, S., Rautio, A., Arvela, P., and Pelkonen, O. (1994). Effects of heme arginate on cytochrome P450mediated metabolism of drugs in patients with variegate porphyria and in healthy men. Clin. Pharmacol. Ther. 56, 9-13.

Namkung, M.J., Faustman-Watts, E., and Juchau, M.R. (1983). Hematin-mediated increases of benzo(a)pyrene mono-oxygenation in maternal, fetal and placental tissues of inducible and non-inducible mouse strains. Dev. Pharmacol. Ther. 6 , 199-206.

Näslund, B.M.A., Glauman, H., Warner, M., Gustafsson, J.A., and Hansson, T. (1988). Cytochrome P450 b and $\mathrm{c}$ in the rat brain and the pituitary gland. Mol. Pharmacol. 33, 31-37.

Nelson, D.R. (2004). P450 nomenclature and overview. URL: http://drnelson.utmem.edu/cytochromep450.html.

Omiecinski, C.J. and Juchau, M.R. (1980). Activators of cytochrome P-450 dependent monooxygenation reactions. Proc. West. Pharmacol. Soc. 23, 9-10.

Omiecinski, C.J., Namkung, M.J., and Juchau, M.R. (1980). Mechanistic aspects of the hematin-mediated increases in brain monooxygenase activities. Mol. Pharmacol. 17, 255-232.

Ourlin, J.C., Handschin, C., Kaufmann, M., and Meyer, U.A. (2002). A link between cholesterol levels and phenobarbital induction of cytochromes P450. Biochem. Biophys. Res. Commun. 291, 378-384.

Padmanaban, G., Venkateswar, V., and Rangarajan, P.N. (1989). Haem as a multifunctional regulator. Trends Biochem. Sci. 14, 492-496.

Park, S.S., Fujino, T., Guengerich, F.P., and Gelboin, H.V. (1982). Monoclonal antibodies that inhibit enzyme activity of 3methylcholanthrene-induced cytochrome P-450. Cancer Res. 42, 1798-1808.

Rangarajan, P.N. and Padmanaban, G. (1989). Regulation of cytochrome $P$-450b/e gene expression by a heme- and phenobarbitone-modulated transcription factor. Proc. Natl. Acad. Sci. USA 86, 3963-3967.

Reed, C.J., van den Broeke, L.T., and De Matteis, F. (1989). Drug-induced protoporphyria in the olfactory mucosa of the hamster. J. Biochem. Toxicol. 4, 161-164.

Sambrook, J., Fritsch, E.F., and Maniatis, T. (1989). Molecular Cloning. (Cold Spring Harbor, NY, USA: Cold Spring Harbor Laboratory Press).

Sassa, S. (2002). The porphyrias. Photodermatol. Photoimmunol. Photomed. 18, 56-67.

Schuurmans, M.M., Hoffmann, F., Lindberg, R.L., and Meyer, U.A. (2001). Zinc mesoporphyrin represses induced hepatic 5 -aminolevulinic acid synthase and reduces heme oxygenase activity in a mouse model of acute hepatic porphyria. Hepatology 33, 1217-1222.

Sultana, S., Nirodi, C.S., Ram, N., Prabhu, L., and Padmanaban, G. (1997). A 65-kDa protein mediates the positive role of heme in regulating the transcription of CYP2B1/B2 gene in rat liver. J. Biol. Chem. 272, 8895-8900.

Thuerl, C., Otten, U., Knoth, R., Meyer, R.P., and Volk, B. (1997). Possible role of cytochrome P450 in inactivation of testosterone in immortalized hippocampal neurons. Brain Res. 762, 47-55.

Zhang, L., Hach, A., and Wang, C. (1998). Molecular mechanism governing heme signaling in yeast: a higher-order complex mediates heme regulation of the transcriptional activator HAP1. Mol. Cell Biol. 18, 3819-3828.

Received July 14, 2005; accepted August 31, 2005 